\title{
Indicators related to physical disability and diagnosis of leprosy
}

\author{
Indicadores relacionados a incapacidade física e diagnóstico de hanseníase
}

Heloisy Alves de Medeiros Leano ${ }^{1}$, Kleane Maria da Fonseca Azevedo Araújo ${ }^{1}$, Rayssa Nogueira Rodrigues ${ }^{1}$, Isabela de Caux Bueno ${ }^{1}$, Francisco Carlos Félix Lana ${ }^{1}$

Objective: to analyze the trend of epidemiological indicators of leprosy related to diagnosis and physical disability. Methods: ecological study of time series. The secondary data were extracted from the Brazilian Notifiable Diseases Information System. Prais-Winsten generalized linear analysis was used for trend analysis. Results: 240,028 new cases of leprosy were analyzed. The Northeast region showed a decreasing annual trend $(-2.9 \%)$ for general detection. As for disability, there are differences among the states of Bahia (4.9\%), Alagoas (4.1\%), Piauí (2.5\%), Maranhão (2.2\%) and Ceará (2.1\%), which presented increasing trend to grade 2 ratio in the general population. Bahia (9.5\%), Sergipe (6.6\%) and Maranhão (4.9\%) also presented an increasing trend to grade 2 among children. Conclusion: the Northeast region has remained at a very high endemicity level for leprosy with a difference in the distribution of the disease among the states. It was shown active transmission of the bacillus, late diagnosis and underreporting in the region.

Descriptors: Leprosy; Child; Disabled Persons; Epidemiologic Measurements; Neglected Diseases.

Objetivo: analisar a tendência dos indicadores epidemiológicos da hanseníase relacionados ao diagnóstico e incapacidade física. Métodos: estudo ecológico de séries temporais. Os dados secundários foram extraídos do Sistema de Informação de Agravos de Notificação brasileiro. Utilizou-se análise linear generalizada de PraisWinsten para análise de tendência. Resultados: analisou-se 240.028 casos novos de hanseníase. O Nordeste apresenta tendência anual decrescente $(-2,9 \%)$ para detecção geral. Quanto à incapacidade há diferenças entre os estados: Bahia (4,9\%), Alagoas (4,1\%), Piauí $(2,5 \%)$, Maranhão $(2,2 \%)$ e Ceará $(2,1 \%)$ que apresentam tendência crescente para proporção de grau 2 na população geral. Bahia $(9,5 \%)$, Sergipe $(6,6 \%)$ e Maranhão $(4,9 \%)$ também apresentam tendência crescente para grau 2 entre crianças. Conclusão: o Nordeste se mantém em nível de muito alta endemicidade para hanseníase com diferença na distribuição da doença entre os estados. Evidencia-se transmissão ativa do bacilo, diagnóstico tardio e subnotificação na região.

Descritores: Hanseníase; Criança; Pessoas com Deficiência; Medidas em Epidemiologia; Doenças Negligenciadas.

$\overline{{ }^{1} \text { Universidade Federal de }}$ Minas Gerais. Belo Horizonte, MG, Brazil. 


\section{Introduction}

Leprosy is still a major public health problem. The World Health Organization has detected a slight decrease in cases in the African Continent and in the Americas, and in South-East Asia, places that have a greater burden of the disease, but overall there has been a marginal increase in new cases of the disease in the year $2016^{(1)}$.

The diagnosis of leprosy has some difficulties and often the clinical picture is confused with other skin diseases or not valued, a situation that favors the late diagnosis of cases and, consequently, the occurrence of physical disabilities that can even evolve into deformities ${ }^{(2)}$. Physical disability is classified into three levels, grade 0,1 and 2, and eyes, hands and feet should be evaluated.

Although it is considered an adult and young-adult disease, given its high incubation time, cases have been recorded in children, a situation that indicates high transmissibility and precocity of exposure to bacillus ${ }^{(3)}$. According to data from the World Health Organization $^{(1)}$, in the year 2015, 8.5\% $(n=18,230)$ of the total cases reported in the world occurred in children under 15 years of age, of whom 1.5\% ( $n=281)$ presented grade 2 disability in diagnosis.

Faced with this problem, a new global strategy was launched ${ }^{(2)}$ to concentrate efforts for timely detection of cases before visible disabilities occur. One of the goals is the absence of disability among new patients under the age of 15 by the year 2020 .

Brazil is the second in absolute numbers of leprosy cases in the world and responsible for the largest occurrence of cases in the Americas, and has reported, in 2016, 25,218 new cases, of which 1,736 $(6.9 \%)$ occurred in the age group from zero to 14 ye$\operatorname{ars}^{(2)}$. When leprosy occurs in infancy, it can influence the quality of life and interfere in school life, considering the social limitation imposed historically, the discrimination, low self-esteem and stigma ${ }^{(4)}$.

There is evidence that social inequality is directly related to increased susceptibility to leprosy ${ }^{(5-6)}$, since inequalities produce unmet social needs that undermine community health.

The territorial extension of Brazil encompasses social heterogeneities between the regions, as well as areas that concentrate a greater number of cases of leprosy. The Northeastern region, the poorest in the country, registered, in 2015, 53.1\% of new cases of leprosy in children under 15 years of age ( 7.64 cases per 100 thousand inhabitants), while the South region, one of the richest, registered only $0.6 \%$ ( 0.20 cases per 100 thousand inhabitants). In addition, the detection rate in this age group in the Northeast region is almost double the rate found for the country ${ }^{(1)}$.

Considering the need to deepen knowledge about the behavior of this endemic disease in the Brazilian Northeast, with a view to contributing to effective actions to eliminate it as a public health problem, this study aims to analyze the trend of the epidemiological indicators of leprosy related to diagnosis and physical disability.

\section{Methods}

This is an ecological study of time series carried out in the states of Northeast Brazil. It is composed of 1,717 municipalities distributed in nine states. This region has the lowest Human Development Index in the country, and all its states (Maranhão, Piauí, Ceará, Rio Grande do Norte, Paraíba, Pernambuco, Alagoas, Sergipe and Bahia) are ranked among the last twelve positions in the 2010 human development ranking.

The study population comprised 240,888 new cases of leprosy, of which 21,154 were children younger than 15 years of age, notified between 2001 and 2015 in the Notifiable Diseases Information System, the main survey system for collecting and analyzing national data on leprosy in Brazil. The data were made available by a protocol through the Citizen Information Service Electronic System of the Federal Government. We excluded the cases considered as diagnostic error in the database, with transfer to another state or country, duplicity and inconsistency of data. Popula- 
tion data were obtained from the estimates made by the Brazilian Institute of Geography and Statistics.

For the treatment of data we used the Microsoft Office Excel software (2010), which included the structuring of a database with the following indicators $^{(7)}$ : 1- annual detection rate of new leprosy cases in the population aged zero to 14 years per 100,000 inhabitants, 2 - annual detection rate of new cases of leprosy per 100,000 inhabitants, 3 - proportion of leprosy cases with grade 2 of physical disability at the time of diagnosis among the new cases detected and evaluated, 4 - proportion of new cases of leprosy with degree of physical disability assessed in the diagnosis.

We also used the indicator: 5-proportion of children younger than 15 years among new cases, and an evaluation of two other indicators was proposed: 6-proportion of leprosy cases with grade 2 of physical disability at the time of diagnosis among new cases from zero to 14 years of age detected and evaluated (Numerator: new cases with degree 2 of physical incapacity in the diagnosis from zero to 14 years, detected in the year of evaluation, Denominator: new cases from zero to 14 years old with a degree of physical disability assessed, living in the same place and period. Multiplying factor: 100), and proportion of new cases of leprosy with physical disability assessed at diagnosis in the population aged zero to 14 years (Numerator: new cases of leprosy from zero to 14 years with the degree of physical disability assessed at diagnosis, detected in the year of evaluation, Denominator: new cases of leprosy in the population from zero to 14 years, living in the same place and diagnosed in the year of evaluation; Multiplication factor: 100).

The parameters for incidence in children under 15 years were: hyperendemic $(\geq 10.00)$; very high (9.99 to 5.00); high (4.99 to 2.50); medium (2.49 to $0.50)$; and low $(<0.50)$; for general detection: hyperendemic ( $>40.0$ ), very high (20.00 to 39.99), high (10.00 to 19.99), medium (2.00 to 9.99), low ( $<2$ ); for the proportion grade 2 of physical disability detected among the new cases evaluated in the diagnosis: high
( $\geq 10.0 \%)$, medium (5 to $9.9 \%$ ) and low: $(<5.0 \%)$, and the proportion of new cases with degree of disability assessed at diagnosis: good $\geq 90.0 \%$; average $\geq 75$ to $89.9 \%$; poor $<75.0 \%{ }^{(7)}$. As there are no parameters for the proportion of physical disability assessed at diagnosis and grade 2 of disability detected at diagnosis among new cases of children younger than 15 years of age, we used the same parameters used for the general population.

For the trend analysis, the Stata software (version 14) was used, and the autoregressive model of Prais-Winsten was used, in which the independent variable (x) was the year (2001 to 2015) and the dependent variables (y) were the epidemiological and operational indicators. This model is indicated to correct the serial autocorrelation in time series ${ }^{(8)}$.

Initially, the logarithmic transformation of the $y$ values was performed to reduce the heterogeneity of the residue variance of the regression analysis ${ }^{(8)}$. Then, the Prais-Winsten model was applied.

In order to identify the annual percentage change (APC), the values of the coefficient b1 corresponding to each of the indicators were applied to the following formula: APC $=-1+10^{[b 1]^{*}} 100 \%$. Finally, the $95 \%$ confidence intervals $(95 \% \mathrm{CI})$ of the variation measures were calculated by applying the following formulas: $95 \% \mathrm{CI}_{\text {minimum }}=-1+10\left[b 1-t^{*} e\right] * 100 \%$ ); and $95 \% \mathrm{CI}_{\text {maximum }=}-1+10^{\left[b 1+t^{*} e\right] *} 100 \%$.

The values of the coefficient $b 1$ and $e$ (standard error) were generated by the statistical analysis program, $t$ refers to t-student test and corresponds to 14 degrees of freedom (2.145), which refers to 15 years of analysis, with a $95 \%$ level of confidence. But for indicators involving disability, data of year 2007 were removed because in this year there was a change in the information system regarding the definition of grade 2 deficiency and this could have caused data inconsistency ${ }^{(9)}$. So the t-student used equals 13 degrees of freedom (2.160).

From this calculation, the temporal evolution of the indicators can be interpreted as growing trend, when the average annual rate of change was signifi- 
cantly positive; declining trend, when the rate of variation was significantly negative; and stationary, when the null hypothesis is accepted that there is no significant difference between the value of the variation and zero.

The study complied with the formal requirements contained in the national and international regulatory standards for research involving human beings.

\section{Results}

The detection rate in the age range from zero to 14 years in the Northeast region ranged from hyperendemic to very high endemic level (maximum: 11.70; minimum: 7.47) in the analysis period. The states of Maranhão (maximum: 29.93; minimum: 16.75) and Pernambuco (maximum: 14.97; minimum: 10.47) presented hyperendemic rates for the indicator during the whole period, in addition to the highest proportion of children under 15 years among the new cases of leprosy in the region. None of the Northeastern states presented a low endemic level in the study period for disease incidence in children under 15 years of age.

As for the general detection rate, the Northeast region remained at a very high endemic level (maximum: 37.34; minimum: 22.86), as well as Ceará (maximum: 36.43; minimum: 20.74). The states of Maranhão (maximum: 90.00; minimum: 51.42), Piauí (maximum: 61.46; minimum: 32.53) and Pernambuco (maximum: 42.91; minimum: 25.54) has been classified as hyperendemic for leprosy, but only Maranhão had still remained in this parameter in 2015.

In relation to grade 2 of physical disability among those under 15 years of age, Rio Grande do Norte (maximum: 12.3\%; minimum: 5.7\%) and Alagoas (maximum: $11.7 \%$; minimum: $3.6 \%$ ) have shown a cyclical variation of this indicator, varying from high to low proportion, although they had not presented the highest general detection rates of the region.

The trend of leprosy in the Northeast Region $(\mathrm{p}<0.001)$ has showed a decreasing behavior for the general detection rate, but stationary behavior $(\mathrm{p}=0.095)$ among those younger than 15 years (Table 1). It is noteworthy that only Maranhão; Piauí, Paraíba and Pernambuco has shown a decreasing trend for both indicators. In relation to the proportion of children under 15 years of age among all new cases of leprosy, it is noteworthy that only Piauí ( $p=0.001)$, Paraíba $(\mathrm{p}<0.001)$, and Bahia $(\mathrm{p}=0.003)$ have had decreasing trend.

Table 1 - Trend and percentage annual variation of leprosy detection rates in children under 15 years of age, general population, and proportion of cases in children under 15 years

\begin{tabular}{|c|c|c|c|c|}
\hline Indicator/Location & $(\%)$ & $95 \% \mathrm{CI}$ & $\mathbf{p}$ & Trend \\
\hline \multicolumn{5}{|c|}{$\begin{array}{l}\text { Detection rate of new cases in the } \\
\text { population from zero to } 14 \text { years }\end{array}$} \\
\hline Northeast region & -1.7 & $(-3.7 ; 0.5)$ & 0.091 & Stationary \\
\hline Ceará & -1.7 & $(-4.3 ; 0.9)$ & 0.182 & Stationary \\
\hline Rio Grande do Norte & 3.0 & $(-6.6 ; 13.4)$ & 0.530 & Stationary \\
\hline Alagoas & -1.0 & $(-4.4 ; 2.6)$ & 0.565 & Stationary \\
\hline Sergipe & -3.6 & $(-7.9 ; 0.9)$ & 0.111 & Stationary \\
\hline Bahia & -0.2 & $(-3.8 ; 3.6)$ & 0.931 & Stationary \\
\hline Pernambuco & -2.0 & $(-2.6 ;-1.4)$ & $<0.001^{*}$ & Decreasing \\
\hline Maranhão & -3.1 & $(-5.0 ;-1.1)$ & $0.006^{*}$ & Decreasing \\
\hline Piauí & -4.9 & $(-6.8 ;-3.0)$ & $<0.001^{*}$ & Decreasing \\
\hline Paraíba & -6.9 & $(-8.8 ;-5.0)$ & $<0.001^{*}$ & Decreasing \\
\hline \multicolumn{5}{|c|}{$\begin{array}{l}\text { Detection rate of new cases of } \\
\text { leprosy in the general population }\end{array}$} \\
\hline Northeast region & -2.9 & $(-4.2 ;-1.6)$ & $<0.001^{*}$ & Decreasing \\
\hline Bahia & -0.9 & $(-3.8 ; 2.1)$ & 0.531 & Stationary \\
\hline Rio Grande do Norte & -1.2 & $(-4.0 ; 1.7)$ & 0.376 & Stationary \\
\hline Alagoas & -2.1 & $(-3.4 ;-0.8)$ & $0.004^{*}$ & Decreasing \\
\hline Sergipe & -2.6 & $(-3.9 ; 1.2)$ & $0.001^{*}$ & Decreasing \\
\hline Pernambuco & -3.3 & $(-4.0 ;-2.6)$ & $<0.001^{*}$ & Decreasing \\
\hline Maranhão & -3.6 & $(-4.7 ;-2.5)$ & $<0.001^{*}$ & Decreasing \\
\hline Ceará & -3.6 & $(-4.4 ;-2.8)$ & $<0.001^{*}$ & Decreasing \\
\hline Paraíba & -4.2 & $(-6.1 ;-2.3)$ & $<0.001^{*}$ & Decreasing \\
\hline Piauí & -4.5 & $(-5.7 ;-3.3)$ & $<0.001^{*}$ & Decreasing \\
\hline \multicolumn{5}{|c|}{$\begin{array}{l}\text { Proportion of cases in children } \\
\text { under } 15 \text { among all new cases }\end{array}$} \\
\hline Northeast region & -0.5 & $(-1.9 ; 0.4)$ & 0.236 & Stationary \\
\hline Maranhão & -0.7 & $(-1.9 ; 0.3)$ & 0.148 & Stationary \\
\hline Ceará & -0.1 & $(-2.0 ; 1.8)$ & 0.878 & Stationary \\
\hline Rio Grande do Norte & 2.3 & $(-5.6 ; 10.9)$ & 0.551 & Stationary \\
\hline Pernambuco & 0.1 & $(-0.7 ; 0.5)$ & 0.771 & Stationary \\
\hline Alagoas & -0.5 & $(-4.0 ; 3.2)$ & 0.787 & Stationary \\
\hline Sergipe & -2.9 & $(-6.4 ; 0.7)$ & 0.106 & Stationary \\
\hline Bahia & -1.4 & $(-2.3 ;-0.6)$ & $0.003^{*}$ & Decreasing \\
\hline Piauí & -1.9 & $(-2.8 ;-1.0)$ & $0.001^{*}$ & Decreasing \\
\hline Paraíba & -4.0 & $(-4.8-;-3.2)$ & $<0.001^{*}$ & Decreasing \\
\hline
\end{tabular}


Sergipe $(p=0.044)$ and Maranhão $(p=0.031)$ have shown an increasing trend of the proportion of grade 2 (Table 2) among those under 15 years of age and the states of Bahia ( $\mathrm{p}=0.004)$, Alagoas ( $\mathrm{p}=0.016)$, Piauí $(\mathrm{p}=0.011)$, Maranhão $(\mathrm{p}=0.038)$ and Ceará $(p=0.049)$ have shown this trend in the general population.

Table 2 - Trend and percentage annual variation of the proportion of grade 2 physical disability in the diagnosis of new cases of leprosy in children under 15 years and in the general population

\begin{tabular}{|c|c|c|c|c|}
\hline Indicator/Location & $(\%)$ & $95 \% \mathrm{CI}$ & $\mathbf{p}$ & Trend \\
\hline \multicolumn{5}{|c|}{$\begin{array}{l}\text { Proportion of grade } 2 \text { physical disability } \\
\text { in the population from zero to } 14 \text { years }\end{array}$} \\
\hline Northeast region & 2.8 & $(-0.1 ; 6.8)$ & 0.147 & Stationary \\
\hline Sergipe & 5.5 & $(0.2 ; 11.1)$ & $0.044^{*}$ & Increasing \\
\hline Maranhão & 4.4 & $(0.5 ; 8.4)$ & $0.031^{*}$ & Increasing \\
\hline Piauí & 1.1 & $(-7.0 ; 9.9)$ & 0.780 & Stationary \\
\hline Ceará & 4.8 & $(-2.0 ; 12.1)$ & 0.156 & Stationary \\
\hline Rio Grande do Norte & 2.1 & $(-8.3 ; 13.6)$ & 0.689 & Stationary \\
\hline Paraíba & 1.2 & $(-4.4 ; 7.3)$ & 0.653 & Stationary \\
\hline Pernambuco & 1.2 & $(-5.1 ; 7.9)$ & 0.691 & Stationary \\
\hline Alagoas & -0.7 & $(-8.5 ; 7.7)$ & 0.848 & Stationary \\
\hline Bahia & 8.4 & $(-2.5 ; 9.0)$ & $0.127^{*}$ & Stationary \\
\hline \multicolumn{5}{|c|}{ Proportion of grade 2 physical disability } \\
\hline \multicolumn{5}{|l|}{ in the general population } \\
\hline Northeast region & 2.0 & $(-0.1 ; 4.0)$ & 0.053 & Stationary \\
\hline Bahia & 5.0 & $(1.9 ; 8.1)$ & 0.004 & Increasing \\
\hline Alagoas & 4.1 & $(0.9 ; 7.4)$ & $0.016^{*}$ & Increasing \\
\hline Piauí & 2.5 & $(0.7 ; 4.4)$ & $0.011^{*}$ & Increasing \\
\hline Maranhão & 2.2 & $(0.2 ; 4.3)$ & $0.038^{*}$ & Increasing \\
\hline Ceará & 2.1 & $(0.1 ; 4.2)$ & $0.049^{*}$ & Increasing \\
\hline Rio Grande do Norte & 1.4 & $(-2.1 ; 5.0)$ & 0.401 & Stationary \\
\hline Paraíba & 2.4 & $(-2.3 ; 7.3)$ & 0.267 & Stationary \\
\hline Pernambuco & 1.0 & $(-1.6 ; 3.6)$ & 0.416 & Stationary \\
\hline Sergipe & 4.9 & $(-0.7 ; 10.7)$ & 0.086 & Stationary \\
\hline
\end{tabular}

Regarding the quality of the services for assessment of disability in diagnosis, the Northeast region and its states have an average lower than $90.0 \%$ as regular, except for Piauí and Sergipe (Table 3), and for the population aged 0 to 14 years we also observed an average lower than $90.0 \%$, except for the states of Piauí, Ceará and Pernambuco.

Table 3 - Average of the proportion of physical disability assessment at the time of leprosy diagnosis in the general population and in children under 15 years of age

\begin{tabular}{lcc}
\hline Location & $\begin{array}{c}\text { Overall average } \\
\text { (\%) }\end{array}$ & $\begin{array}{c}\text { Average from zero } \\
\text { to 14 years (\%) }\end{array}$ \\
\hline Northeast region & 85.7 & 88.0 \\
Maranhão & 80.5 & 83.3 \\
Piauí & 91.4 & 94.0 \\
Ceará & 86.9 & 92.2 \\
Rio Grande do Norte & 82.1 & 85.5 \\
Paraíba & 86.4 & 88.0 \\
Pernambuco & 89.7 & 91.8 \\
Alagoas & 79.7 & 83.4 \\
Sergipe & 95.5 & 89.1 \\
Bahia & 85.4 & 87.4 \\
\hline
\end{tabular}

\section{Discussion}

The interpretation of the results should take into account that this study may present limitations deriving from the use of secondary data, due to possible inconsistency in the quantity and quality of its information. There may have been underreporting of leprosy cases leading to underestimation of detection rates, which means that the epidemiological situation could be even worse than described. In addition, there may have been failures related to the completion of the notification forms by health practitioners and the inadequate typing of data. However, choosing this type of source reduces costs and allows performing analyzes.

The states of Maranhão, Piauí, Paraíba and Pernambuco have presented a decreasing trend both for detection rate in the total population and for those un- 
der 15 years of age. However, in Piauí alone, the speed of reduction is higher among those under 15 years of age. In this sense, Piauí is likely to reduce the disease burden to a considerably lower level in a faster period.

A possible hypothesis for the decrease of the indicator is that there has been an intensified detection caused by a better coverage of the control programs. In fact, there has been an increase in population coverage by family health teams in the last 15 years in these states. Coverage has been maintained above $60.0 \%$ and sustainable since $2006^{(7)}$.

The integration of leprosy control actions in primary health care has been advocated by the Ministry of Health since the implementation of the Family Health Strategy in 1994. However, this integration has stood out after the year 2000 with an increase in the detection rate of new cases, having reached a peak in 2003 , and then gradually declined ${ }^{(10)}$.

Although there has been a declining trend in general detection, the states of Maranhão, Piauí, Ceará and Pernambuco have revealed high detection rates throughout this period. This indicates that coverage of primary care services does not guarantee full access to leprosy control actions. The quality of health care depends on a set of attributes: gateway, access, comprehensiveness, longitudinality, coordination, focus on the person and the family, appreciation of cultural aspects and guidance to the community ${ }^{(11)}$.

Another relevant aspect is the relationship between leprosy and poverty ${ }^{(5,12)}$. The progress in the coverage of the Brazilian income transfer program (Bolsa Família - Family Allowance Program) associated with primary health care coverage has impacted on the decline of the incidence of the disease in Brazil ${ }^{(5)}$.

Due to the long incubation period, leprosy is considered to be an adult disease ${ }^{(3)}$. But in endemic sites, children, considered the most resistant group, become vulnerable as a result of being continually exposed to active transmission foci ${ }^{(13)}$. Thus, evaluating the occurrence of the disease in children under 15 years is important since this indicator reflects the intensity of propagation of Mycobacterium leprae and the impact of the control actions ${ }^{(14)}$, as illness in this age group involves recent transmission ${ }^{(15)}$. Corroborating with our result, it had already been evidenced a decrease of this illness in children under 15 years in Maranhão $0^{(9)}$. In Brazil, there was also a decrease in Pará $^{(9)}$, Mato Grosso ${ }^{(4,9)}$, and in the capital of Cearáa ${ }^{(16)}$. Some countries have also showed a decrease in the trend of the disease in this age group ${ }^{(1,17)}$. But in the states of Pernambuco and Maranhão there has been persistence of active transmission with patterns of hyperendemicity of detection rate among children throughout the study period.

The fact that children under the age of 15 have been ill makes is concerning because it indicates that a significant number of cases have not been detected or treated in a timely manner to break the disease transmission chain ${ }^{(14)}$. In addition, it may be suggested undiagnosed home contact ${ }^{(4)}$. It is worth remembering that the transmission of the disease is not restricted to the household ${ }^{(14)}$, thus, this highlights the important role of extra-household or social contacts in the transmission chain of leprosy.

As part of the strategy for the detection of leprosy and knowledge diffusion, it is necessary articulation with the School Health Program, an intersectoral health and education Brazilian policy instituted in 2007. There has been evidence of the importance of screening research among schoolchildren using serological markers ${ }^{(15)}$, especially in endemic areas, and there is need of further studies on technologies for timely diagnosis.

In this study, the proportion of people aged less than 15 years evaluated as to the degree of disability at diagnosis was considered at average ${ }^{(7)}$. The degree of disability is related to the time of evolution of the disease, which reinforces the need for effectiveness of timely detection of cases by health services ${ }^{(18)}$.

Unlike the stationary trend of the proportion of cases in children under 15 years of age, the proportion of grade 2 in this age group was increasing in the states of Sergipe and Maranhão, pointing to the persistence of late diagnosis and the maintenance of ba- 
cilliferous sources.

In all states, cases of children with grade 2 disability had been reported, and none of the states presented a declining of this indicator. Thus, there may be underreporting of cases of disability in this age group, since not all children have been evaluated at the time of diagnosis. According to a goal established by the World Health Organization ${ }^{(2)}$, by 2020, all countries should eliminate physical disability resulting from leprosy in persons under the age of 15.

The strengthening of disease control actions in primary care is necessary. Further studies should be carried out on the evaluation of the quality of leprosy care services. It is imperative to train the multidisciplinary team and invest in technologies for a timely diagnosis, as well as the continuity of governmental investments in the social field, given its close relationship with the disease.

\section{Conclusion}

The Northeast region remains at a very high endemicity level for leprosy with a difference in distribution among the states. The stationarity character of the trend among children under 15 years of age in states in the region has reached a worrisome level of endemic and this, associated with an increasing proportion of grade 2 disability, including among children under 15, suggests active transmission of the bacillus, late diagnosis and underreporting in this region.

\section{Collaborations}

Leano HAM contributed to the design of the project, data analysis, writing and critical review of the intellectual content and final approval of the version to be published. Araújo KMFA, Rodrigues RN and Bueno IC contributed to data analysis and article writing. Lana FCF contributed to the design of the project, relevant critical review of the intellectual content and final approval of the version to be published.

\section{References}

1. World Health Organization. Global leprosy update, 2016: accelerating reduction of disease burden. [Internet]. 2017 [cited 2017 Nov. 09]; 92(35):501-19. Available from: http://apps.who. int/iris/bitstream/10665/258842/1/WER9235501-519.pdf

2. World Health Organization. Estratégia Global para Hanseníase 2016-2020. Brasília: Organização Pan-Americana da Saúde [Internet]. 2016 [citado 2017 jun. 01]. Disponível em: https://edisciplinas. usp.br/pluginfile.php/3250850/mod_resource/ content/1/9789290225201-Portuguese.pdf

3. Sasidharanpillai S, Binitha MP, Riyaz N, Ambooken B, Mariyath OK, George B, et al. Childhood leprosy: a retrospective descriptive study from Government Medical College, Kozhikode, Kerala, India. Lepr Rev [Internet]. 2014 [cited 2017 June 01]; 85(2):100-10. Available from: https://www.lepra. org.uk/platforms/lepra/files/lr/June14/Lep100110.pdf

4. Freitas BHBM, Cortela DCB, Ferreira SMB. Trend of leprosy in individuals under the age of 15 in Mato Grosso (Brazil), 2001-2013. Rev Saúde Pública. 2017; 51(28). doi: http://dx.doi.org/10.1590/ S1518-8787.2017051006884

5. Nery JS, Pereira SM, Rasella D, Penna MLF, Aquino $\mathrm{R}$, Rodrigues LC, et al. Effect of the Brazilian conditional cash transfer and primary health care programs on the new case detection rate of leprosy. Plos Negl Trop Dis. 2014; 8(11):3357. doi: http://dx.doi.org/10.1371/journal.pntd.0003357

6. Entezarmahdi R, Majdzadeh R, Foroushani AR, Nasehi M, Lameei A, Naieni KH. Inequality of leprosy disability in Iran, clinical or socioeconomic inequality: an extended concentration index decomposition approach. Int J Prev Med [Internet]. 2014 [cited 2017 June 01]; 5(4):41423. Available from: https://www.ncbi.nlm.nih. gov/pmc/articles/PMC4018589/

7. Ministério da Saúde (BR). Secretaria de Vigilância em Saúde. Diretrizes para vigilância, atenção e eliminação da hanseníase com problema de saúde pública: manual técnico-operacional [Internet]. 2016 [citado 2017 jun. 01]. Disponível em: www. saude.pr.gov.br/arquivos/File/retrizesdoManuaTcnicoOperacionaldeHansenase.pdf 
8. Antunes JLF, Cardoso MRA. Uso da análise de séries temporais em estudos epidemiológicos. Epidemiol Serv Saúde. 2015; 24(3):56576. doi: http://dx.doi.org/10.5123/S167949742015000300024

9. Freitas LRS, Duarte EC, Garcia LP. Trends of main indicators of leprosy in Brazilian municipalities with high risk of leprosy transmission, 2001-2012. BMC Infect Dis. 2016; 16(1):472. doi: http:// dx.doi.org/10.1186/s12879-016-1798-2

10. Penna MLF, Grossi MAF, Penna, GO. Country profile: leprosy in Brazil. Lepr Rev [Internet]. 2013 [cited 2017 mai. 12]; 84(4):308-15. Available from: https://www.lepra.org.uk/platforms/lepra/files/ lr/Dec13/Lep308-315.pdf

11. Lanza FM, Vieira NF, Oliveira MMC, Lana FCF. Avaliação da Atenção Instrument for evaluating the actions of leprosy control in Primary Care. Rev Esc Enferm USP. 2014; 48(6):105461. doi: http://dx.doi.org/10.1590/S0080623420140000700013

12. Cabral-Miranda W, Chiaravalloti Neto F, Barrozo LV. Socio-economic and environmental effects influencing the development of leprosy in Bahia, northeastern Brazil. Trop Med Int Health. 2014; 19(12):1504-14. doi: http://dx.doi.org/10.1111/ tmi.12389

13. Oliveira MBB, Diniz LM. Leprosy among children under 15 years of age: literature review. An Bras Dermatol. 2016; 91(2):196-203. doi: http:// dx.doi.org/10.1590/abd1806-4841.20163661
14. Santos SD, Penna GO, Costa MCN, Natividade MS, Teixeira MG. Leprosy in children and adolescents under 15 years old in an urban centre in Brazil. Mem Inst Oswaldo Cruz. 2016; 111(6):359-64. doi: http://dx.doi.org/10.1590/0074-02760160002

15. Barreto JG, Bisanzio D, Guimarães LS, Spencer JS, Vazquez-Prokopec GM, Kitron U, et al. Spatial analysis spotlighting early childhood leprosy transmission in a hyperendemic municipality of the Brazilian Amazon Region. Plos Negl Trop Dis. 2014; 8(2):e2665. doi: https://doi.org/10.1371/ journal.pntd.0002665

16. Brito AL, Monteiro LD, Ramos Junior AN, Heukelbach J, Alencar CH. Temporal trends of leprosy in a Brazilian state capital in Northeast Brazil: epidemiology and analysis by join points, 2001 to 2012. Rev Bras Epidemiol. 2016; 19(1):194-204. doi: http://dx.doi. org/10.1590/1980-5497201600010017

17. Kapata N, Chanda-Kapata P, Grobusch MP, O'Grady J, Bates M, Mwaba P, et al. Leprosy trends in Zambia 1991-2009. Trop Med Int Health. 2012; 17(10):1289-93. doi: https://doi.org/10.1111/ j.1365-3156.2012.03050.x

18. Lana FCF, Fabri ACOC, Lopes FN, Carvalho APM, Lanza FM. Deformities due to leprosy in children under fifteen years old as an indicator of quality of the Leprosy Control Programme in Brazilian Municipalities. J Trop Med. 2013; 8(12):1-6. doi: http://dx.doi.org/10.1155/2013/812793 